\title{
AN APPROACH TO EVALUATE THE HEAT EXCHANGER RETROFIT FOR INSTALLED INDUSTRIAL GAS TURBINES: PART II - ECONOMIC EVALUATION
}

\author{
Waleed Al-Busaidi ${ }^{1}$, Pericles Pilidis ${ }^{2}$ \\ ${ }^{1}$ Researcher in Cranfield University; School of Aerospace, Transport and Manufacturing; Bedfordshire; UK \\ ${ }^{2}$ Head of Propulsion Engineering Centre, Cranfield University, Bedfordshire, UK
}

\begin{abstract}
This is part 2 of the conducted study to develop a new systematic method to evaluate the heat exchanger retrofit on existing industrial gas turbines. A new approach has been introduced and validated in the first part comparing with the measured data. This method was used to optimize the obtained cycle performance characteristics and the generated heat exchanger design options based on technical prospective to attain the highest possible improvement on the simple cycle performance. However, it is essential to consider the economic viability of using the recuperative cycle which will be investigated in thispaper. Although that there are several tools which can be used to achieve that objective, this study uses the Net Present Value (NPV) method due to its simplicity and accuracy. The established technique has been applied for the same described gas turbine cycles in the previous part. Based on the stated assumptions, it was found that by applying the recuperation in the first engine,W6BRC, and at full load and $100 \%$ utilization factor conditions, the payback period has increased by one year by applying over that of simple cycle. Moreover, at the end of the project life, the recuperative cycle of this engine is expected to achieve an increase of $\$ 11 M$ in the NPV over that of simple cycle. This difference between the two cycles becomes greater in the case of the second engine, W7FA, which is ranging between $\$ 33.9 M$ and $\$ 46.8 M$. However, the drop in the availability of the overall recuperative gas turbine by about 18\% over the simple cycle gas turbine causes the NPV of both cycles to be equal. Moreover, this paper includes a sensitivity study to investigate the effects of utilization factor and recuperator effectiveness and pressure drop on the cumulative discounted cash flow.
\end{abstract}

KeyWords:new systematic method,economic viability, Net Present Value, utilization factor, availability $* * *$

\section{INTRODUCTION}

The recuperation is considered as one alternative to improve the low thermal efficiency of the simple gas turbine cycle due to the reduction in the fuel consumption per $\mathrm{kW}$. That can be achieved by using the exhausted turbine gas to heat up the compressor discharge air which results in higher combustor entry temperature. However, this reduction in the burning fuel should be balanced with the rise in the capital cost of the recuperative cycle. Cai Ruixian [1] recommended using a parameter-average heat transfer temperature difference criterion in the recuperator instead of the recuperator effectiveness. The conducted analyses by R.Cai [2] neglected the variation ofpressure drop with average heat transfer temperature which can yield to high uncertainty when large recuperators are used.

The developed approach part 1 consists of three main steps in order to achieve the greatest possible enhancement in the existing cycle performance as shown in figure 1 . The performance of the existing gas turbine models is simulated at the beginning to ensure the appropriate engine selection among the operating units.In order to achieve that, three basic criteria have been used which are: temperature difference between the compressor discharge (CDT) and turbine exhaust gas (EGT), available installation space and initial thermal efficiency.
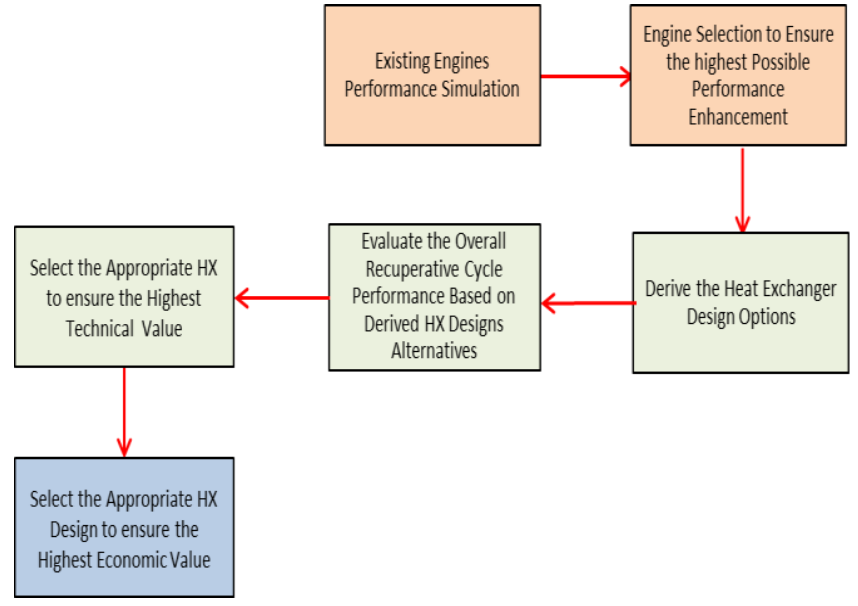

Figure 1: Developed Approach Description

One of the unique features of the new method is the fact that it can be used to generate different heat exchanger designs as a function of the flow velocity in the recuperator sides only. This becomes more useful to evaluate the suitable heat exchanger characteristics according to the obtained overall cycle performance parameters. Finally, an economic analysis is conducted to assess the heat exchanger design alternatives based on the economic prospective. 
There are different tools in the literature which can be used to assess the economic feasibility of this kind of upgrade [3]. However, one of the accurate economic measures is the Net Present Value (NPV) which will be described in this section.

This method is based on one of the fundamentals in the finance. This principle is in a simple way stated that the money received today worth a higher value than the money received in the future. The main reasons behind that can be stated as following [4]:

- The money received today can be invested to earn interest which is expected to achieve a higher return.

- The future incomes are affected by inflation so the purchasing power is expected to be lower.

- The existence of risk in the future.

In this method, the money received in the future $(\mathrm{C})$ is multiplied by the discounted factor (DF) to convert it into a value of today (PV) [5]. The discounted factor is fluctuated between 0 and 1 so that the value of the received money in the future worth less in the present time.

$$
P V=D F_{i} \times C_{i}=\frac{C_{i}}{\left(1+r_{i}\right)^{n_{i}}}
$$

Where: $r_{i}$ is the interest rate (rate of return) at $t_{i}$ years

Moreover, the net present value (NPV) can be calculated by adding the present value (PV) of each year to the initial cash flow [6].

$$
N P V=\sum_{i=1}^{n}\left(D F_{i} \times C_{i}\right)
$$

Where: $n$ is the project life in years.

Based on this method, the cycle NPV has to be positive to be considered economically as profitable project. Furthermore, when the cumulative discounted cash flow reached to zero, it is considered as a breakeven point in which the future income is equal to the initial investment.

\section{ECONOMIC ANALYSIS APPROACH}

The obtained cycle performance parameters in the first part will be used to assess the economic viability of for both simple and recuperative cycles. Besides, the derived alternatives of heat exchanger design will be compared to define the optimum recuperator characteristics for higher economic value.

\subsection{Estimation Of Gas Turbine And Recuperator Capital}

\section{Cost}

The capital cost is including the gas turbine and recuperator costs which are independent of the plant operation. However, the other equipment cost and the installation cost will not be considered in this study since they are common in both cycles. The main performance parameters of the evaluated gas turbine engines are shown in table 1.
Table 1: Design Point Parameters of Simple and Recuperative Cycles at ISO Conditions

\begin{tabular}{|l|l|l|l|l|}
\hline \multirow{2}{*}{ Parameter } & \multicolumn{2}{|l|}{ W6B } & W7FA & \\
\cline { 2 - 5 } & SC & RC & SC & RC \\
\hline Fuel Flow (kg/s) & 2.99 & 2.3567 & 10.5478 & 8.499 \\
\hline $\begin{array}{l}\text { Power Output } \\
\text { (MW) }\end{array}$ & 42.1 & 40.766 & 167.8 & 160.878 \\
\hline $\begin{array}{l}\text { Thermal } \\
\text { Efficiency (\%) }\end{array}$ & 32.64 & 40.11 & 36.89 & 43.89 \\
\hline
\end{tabular}

There are two approaches to estimate the gas turbine cost. The first method is based on the rated power output which has non-linear relationship with the price per $\mathrm{kW}$ as illustrated in figure 2.

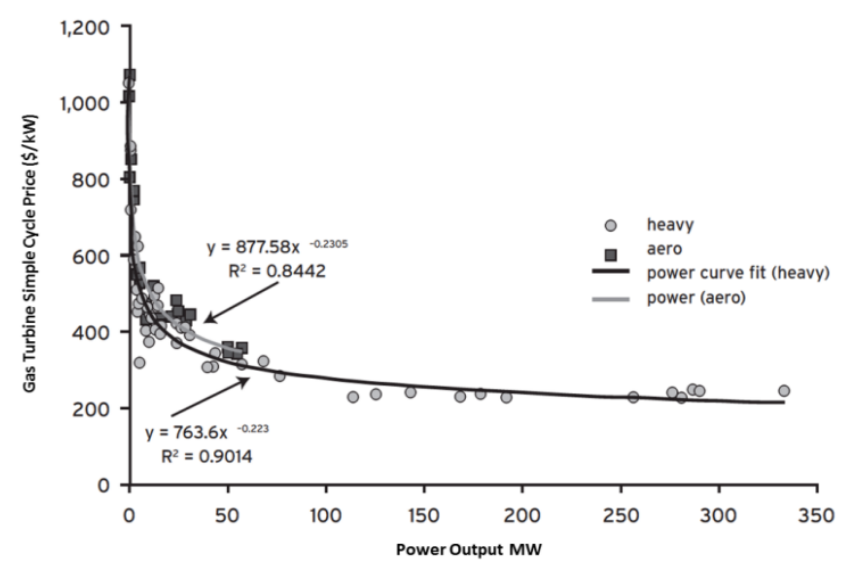

Figure 2: Gas Turbine Price per kW [8]

Ameri et al. [7] introduced another way by estimating the cost of each single component of gas turbine as demonstrated in table 2 including: compressor, combustor and turbine. For the purpose of comparison between the two gas turbines cycles, the first approach will be used in this study. From figure 2 , the rates of $331.6 \$ / \mathrm{kW}$ and $247.4 \$ / \mathrm{kW}$ will be used for W6B and W7FA gas turbines respectively.

Table 2: Capital Cost Estimation of Gas Turbine [7]

\begin{tabular}{cr}
\hline System component & Capital or investment cost functions \\
\hline $\mathrm{Z}_{A C}$ & $\mathrm{Z}_{A C}=\left(\frac{c_{11} \dot{m}_{a}}{c_{12}-\eta_{A C}}\right)\left(\frac{P_{2}}{P_{1}}\right) \ln \left(\frac{P_{2}}{P_{1}}\right)$ \\
$c_{11}=71.10 \$ /(\mathrm{kg} / \mathrm{s}), c_{12}=0.9$ \\
$\mathrm{Z}_{C C}$ & $\mathrm{Z}_{C C}=\left(\frac{c_{21} \dot{m}_{a}}{c_{22}-\frac{P_{4}}{P_{3}}}\right)\left[1+\exp \left(c_{33} T_{G T I T}-c_{24}\right)\right]$ \\
& $c_{21}=46.08, c_{33}=0.995, c_{24}=26.4$ \\
$\mathrm{Z}_{G T}$ & $\mathrm{Z}_{G T}=\left(\frac{c_{31} \dot{m}_{g}}{c_{32}-\eta_{G T}}\right) \ln \left(\frac{P_{C}}{P_{D}}\right)\left[1+\exp \left(c_{33} T_{3}-c_{34}\right)\right]$ \\
\hline & $c_{31}=479.34, c_{32}=0.92, c_{34}=54.4$ \\
\hline
\end{tabular}

Since there is no standard approach to estimate the purchase cost of heat exchangers, the recuperator cost of W6BRC will be considered as provided by the manufacture $(\$ 14 \mathrm{M})$ which can be used to derive the capital cost of W7FARC engine's recuperator per heat transfer area unit.However and since the relationship between the recuperator cost and effective heat transfer area is not really linear so three cases will be considered to evaluate the recuperator cost of W7FARC engine as shown in table 3 . 
Table 3: EstimatedCapital Costs of Gas Turbine and Recuperator

\begin{tabular}{|l|l|l|l|l|}
\hline $\begin{array}{l}\text { Engine } \\
\text { Model }\end{array}$ & $\begin{array}{l}\text { Gas Turbine Cost } \\
(\$ \mathbf{M})\end{array}$ & \multicolumn{3}{|l|}{ Recuperator Cost (\$M) } \\
\hline \multirow{2}{*}{ W6BRC } & 13.960 & 14 & \multicolumn{3}{|l|}{} \\
\hline \multirow{2}{*}{ W7FARC } & \multirow{2}{*}{41.514} & Linear & $80 \% \mathrm{~L}$ & $60 \% \mathrm{~L}$ \\
\cline { 3 - 6 } & & 32.293 & 25.834 & 19.376 \\
\hline
\end{tabular}

The highest capital cost is estimated based on a linear relationship while the other two cases are based on $20 \%$ and $40 \%$ lower than the linear value respectively. So, the actual recuperator capital cost is expected to be in this range.

\subsection{Operation and Maintenance Costs Estimations}

The Maintenance cost (MC) of simple cycle power plants varies based on several factors such as: the component life cycle, mode of operation and capital investment. For simplicity, the maintenance cost is estimated based on the power output and running time.

The maintenance cost of the simple cycle gas turbine is considered to be $0.0028 \$ / \mathrm{kWh}$ based on the recommended values for such configuration. However, there is no specific value of the maintenance cost (MC) of the recuperative cycle. So, the simple approach is used in this study by considering an additional of 5\% and $20 \%$ over that of simple cycle maintenance cost.

One of the operation costs of the plant is the fuel price which is affected by the calorific value of the fuel. Moreover, the calorific value of the natural gas varies from $43 \mathrm{MJ} / \mathrm{kg}$ to $50 \mathrm{MJ} / \mathrm{kg}$ based on the percentage of methane. Thus, the economic study is carried using a calorific value of $43 \mathrm{MJ} / \mathrm{Kg}$.

Additionally, the fuel cost is also fluctuated over the years as a result of many factors. However and in order to make the economic analysis simple, a constant value of fuel cost has been used which is $4 \$ / M M B T U(0.163 \$ / \mathrm{kg})$.

\subsection{Electricity Price Sale}

Although a part of the generated electricity is used internally within the company, the full of power output is assumed to be sold to the grid. Moreover, the electricity price in reality is fluctuating based on the operating time and power demand. Furthermore, the electricity tariff is affected by the ambient temperature so that the power is sold at a higher tariff price at high ambient temperatures. However, a constant value of the electricity price is used in this study which is $0.06 \$ / \mathrm{kWh}$ and it can be considered as an average value.

\section{ECONOMIC ANALYSIS}

The conducted economic optimization is based on the following assumption:

- The discount rate is assumed to be constant and it equals to $8 \%$

- Since this cycle is expected to operate in harsh conditions where the average temperature is roughly $29^{\circ} \mathrm{C}$. The economic analysis has been carried assuming a constant ambient temperature $\left(29^{\circ} \mathrm{C}\right)$.

- The project life is assumed to be 25 years with a commissioning period of one year.

- The income and $\mathrm{CO}_{2}$ taxes have not been considered. However, this value can be subtracted from the yearly return wealth for necessary.

- The recuperators are assumed to be suitable for outdoor installation hence no additional cost for the recuperator building has been considered.

To investigate the economic feasibility of recuperation, both simple and recuperative cycles are compared economically based on the previous stated assumptions.Figure 3 illustrates the cumulative discounted cash flow (DCF) of both simple and recuperative cycles of W6B engine at full load and $100 \%$ utilization factor conditions. It is clearly shown that during the first eight years, the net present value (NPV) of simple cycle is higher than that of recuperative cycle as effect of initial capital cost.

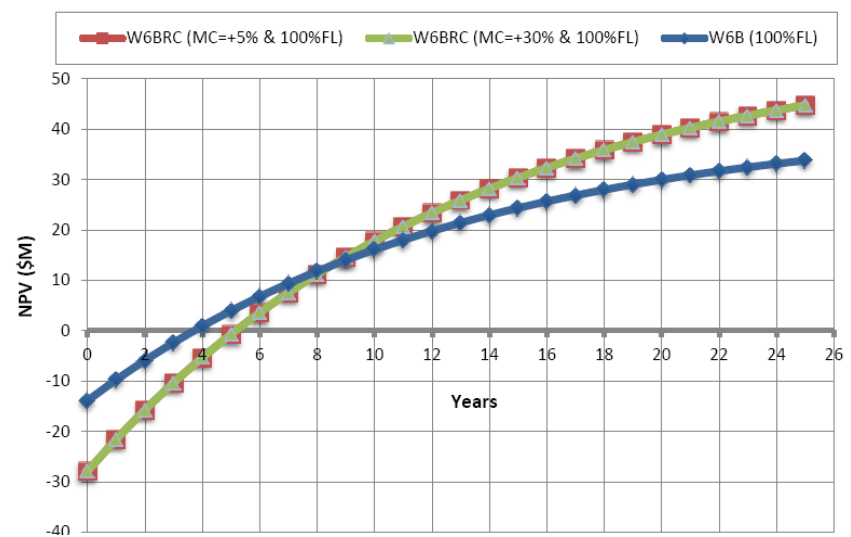

Figure 3: Cumulative DCF of W6B and W6BRC at Full Load

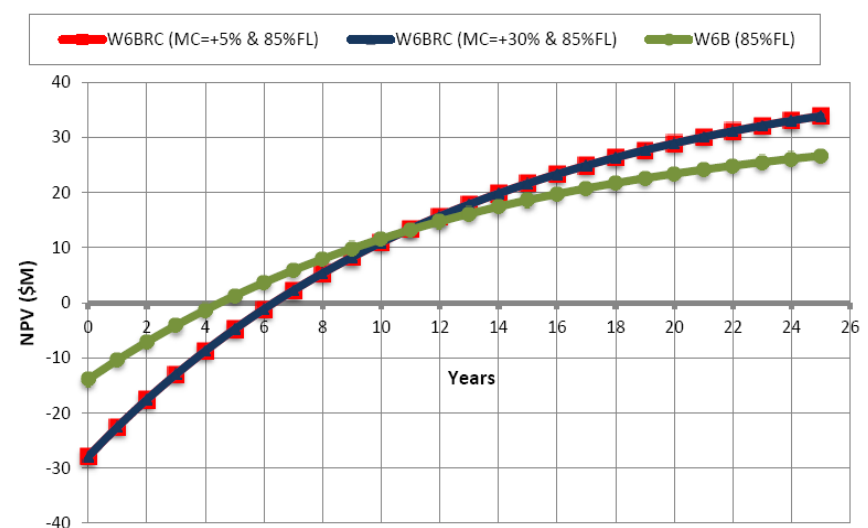

Figure 4: Cumulative CDF of W6B and W6BRC at $85 \% \mathrm{FL}$

The breakeven point of the simple cycle occurs at the fourth year while it occurs at the fifth year in the case of recuperative cycle. However, this extend in the payback period of the recuperative cycle has to be considered in terms of the gas turbine availability which strongly influenced by the downtime. Moreover, the effect of maintenance cost is not significant comparing with the power revenue and fuel cost. However, at the end of the project period, the NPV of the simple cycle reached to 
$\$ 33.8 \mathrm{M}$ comparing with $\$ 44.796 \mathrm{M}$ and $\$ 44.77 \mathrm{M}$ of recuperative cycle at $5 \%$ and $30 \%$ increase in the maintenance cost respectively.

Looking to figure 4 and at $85 \%$ of the full load capability, the payback period of W6BRC has increased to six years. Furthermore, the cumulative DCF of recuperative cycle is taking about 11 years to increase over that of simple cycle. Besides, the expected increase in the NPV of the recuperative cycle at the end of the project life is approximately $\$ 7.23 \mathrm{M}$

Moving to W7FA engine, figure 5 and 6 show the cumulative discounted cash flow of the three cases of capital cost at full utilization factor. It is clear that the recuperative cycle in general can recover the higher increase in its capital cost over that of simple cycle rapidly and in a shorter period of time.

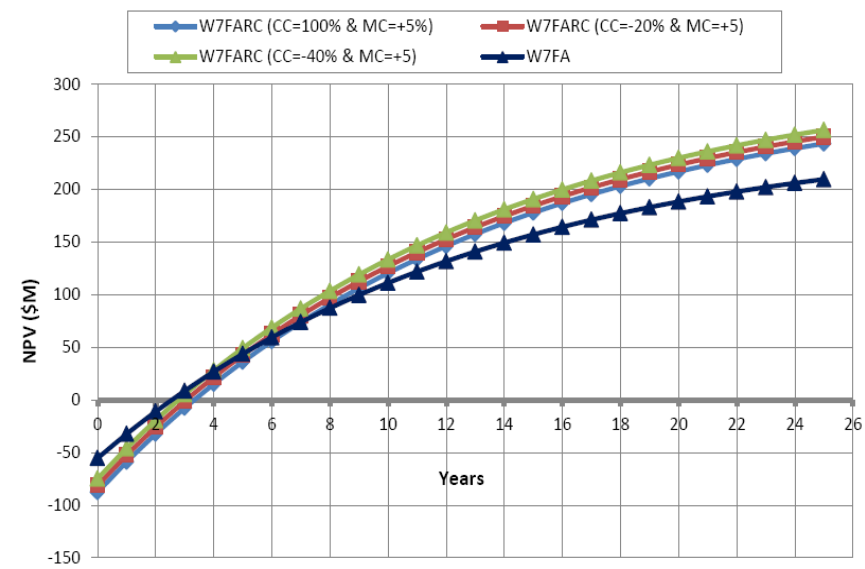

Figure 5: NPV of W7FA and W7FARC at Full Load and $+5 \% \mathrm{MC}$

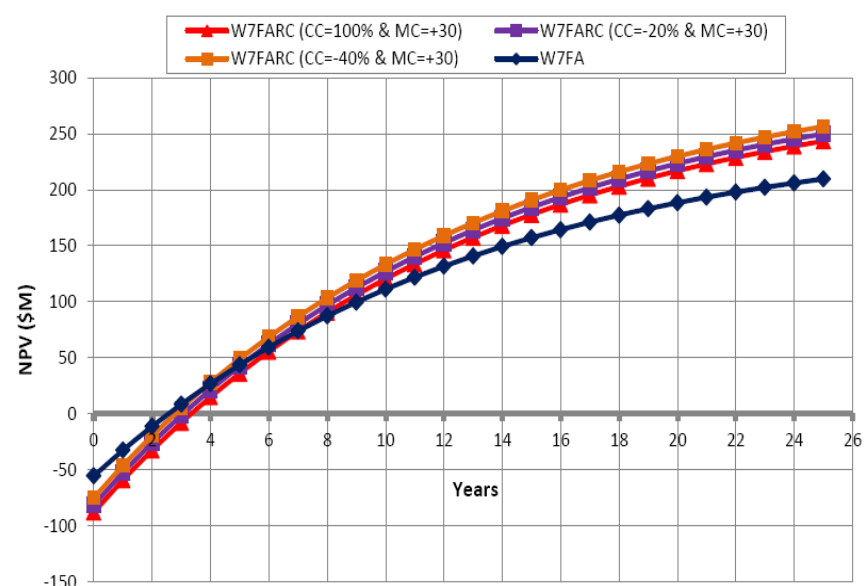

Figure 6: NPV of W7FA and W7FARC at Full Load and $+30 \% \mathrm{MC}$

The breakeven points of both cycles are close to each other which are approximately at the end of the second year.In the case of $100 \%$ of linear capital cost, the net present value (NPV) of recuperative cycle will be equal to that of simple cycle at the sixth year while that happens at the fifth and fourth year when the recuperator capital cost is less than the linear value by $20 \%$ and $40 \%$ respectively.

Looking to the NPV at the end of project life, the recuperation in the case of linear capital cost is expected to raise the cumulative discounted cash flow by about $\$ 33.9$ million over that of simple cycle. This difference is reached to $\$ 46.8$ million when the capital cost is considered to be $60 \%$ of the linear value which is much greater than that of W6B engine.This is mainly due to the fact that the recuperator of W7FARC has been designed with the same pressure drop as W6BRC recuperator which is relatively low if it is compared with the power output of W7FARC gas turbine.

Considering the effect of the maintenance cost, figure 6 demonstrates the net present value at $30 \%$ increase in the maintenance cost of simple cycle. The influence of the maintenance cost is still insignificant which reduces the net present value by about $0.04 \%$ comparing with the first case.

\subsection{Utilization Factor effect}

One of the important parameters in such study is the utilization factor which presents the percentage of the total running time of the gas turbine. Running the gas turbine at low utilization factor causes that the gas turbine cycle will not be able to recover its initial capital cost within the project life. This will result in negative cumulative discounted cash flow as shown in figures 7, 8, 9 and 10 .

Figure 7 illustrates that at full load condition, the breakeven utilization factor of W6B is $30 \%$ while it increases to $40 \%$ in the case of recuperative cycle.

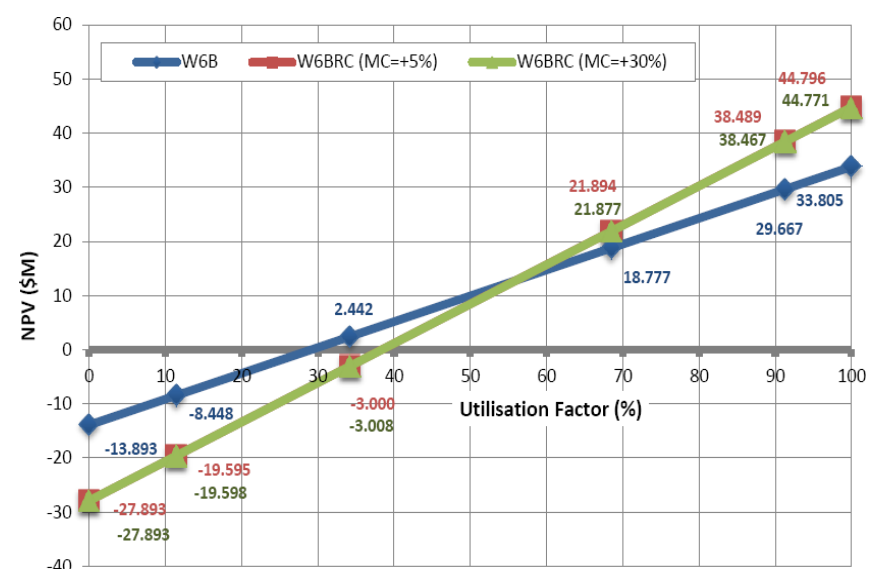

Figure 7: Effect of Utilization Factor on NPV of W6B and W6BRC at Full Load

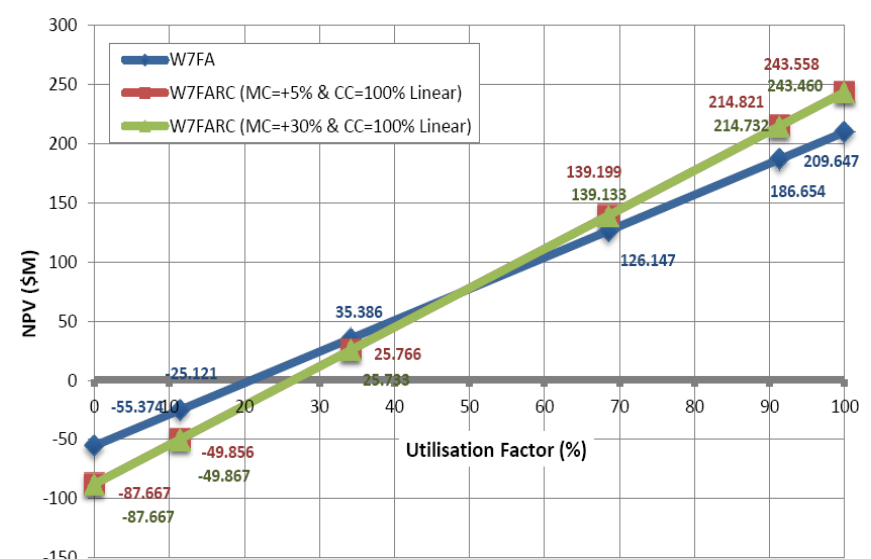

Figure 8:Effect of Utilization Factor on NPV of W7FA and W7FARC at Full Load and Linear Capital Cost 
This is expected since the capital cost of recuperative cycle is relatively higher so a longer running time is required to recover the initial investment using the generated electricity revenue. Moreover, investing in recuperation will not exceed the return wealth of the simple cycle until the gas turbine is running with at least $55 \%$ utilization factor. However, as the utilization factor increases above that point, the NPV of the recuperative cycle is increasing significantly. Moving to figure 8 , at full load condition and by considering the highest possible capital cost of its recuperator, the breakeven utilization factors of W7FA and W7FARC are $20 \%$ and $25 \%$ respectively. These values are quite lower than that of W6B and W6BRC although that the capital costs of W7FA and W7FARC are relatively higher. The main reason behind that is that the thermal efficiencies and power outputs of W7FA and W7FARC are significantly greater and that helps to achieve higher revenue in a shorter running time.

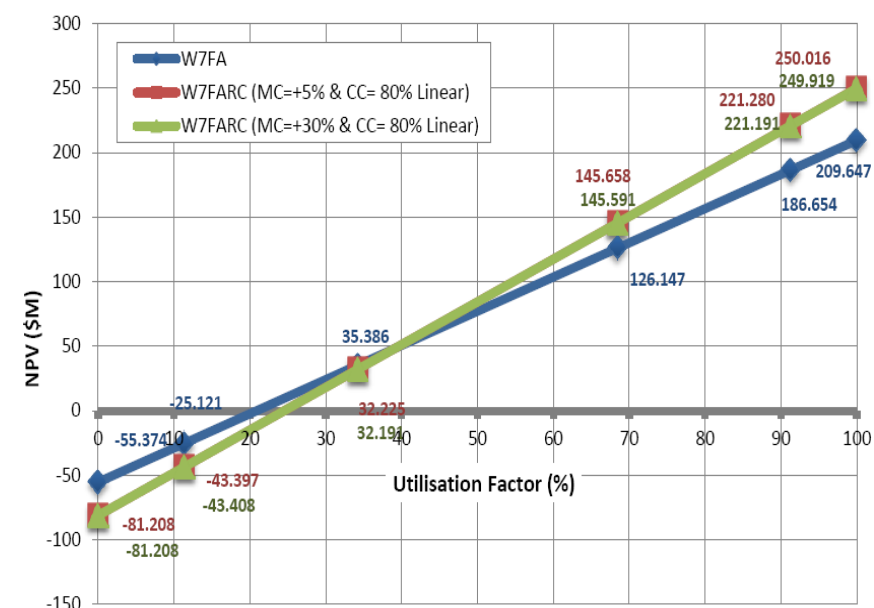

Figure 9: Effect of Utilization Factor on NPV of W7FA and W7FARC at Full Load and Non-Linear Capital Cost

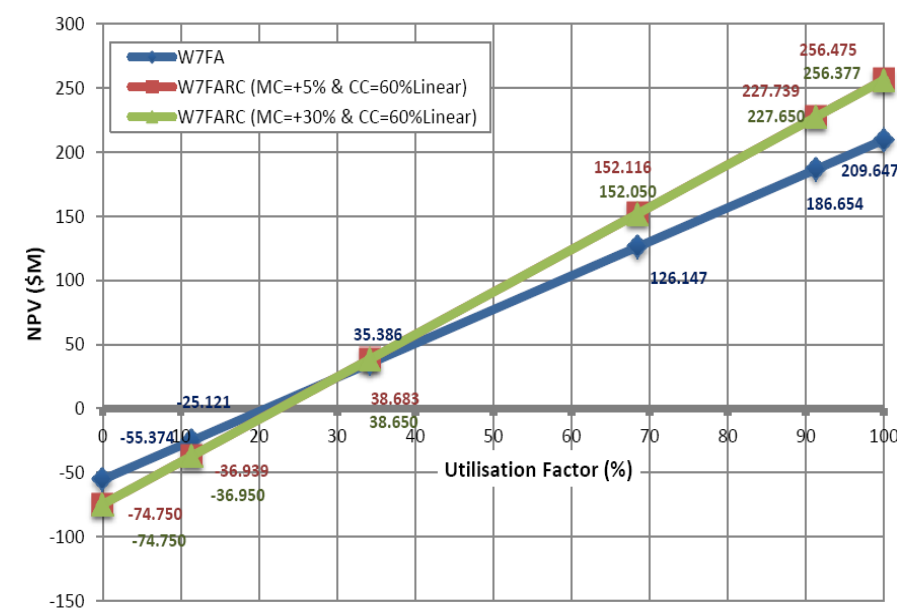

Figure 10: Effect of Utilization Factor on NPV of W7FA and W7FARC at Full Load and Non-Linear Capital Cost

Besides, the minimum required utilization factor which enables the recuperative cycle of W7FA to achieve a higher cumulative DCF comparing with that of simple cycle is $50 \%$. This value has been shifted to the left side in the case of non-linear capital cost of W7FARC recuperator as shown in figures 9 and 10 . In the case of $80 \%$ and $60 \%$ of the linear capital cost value, running the recuperative gas turbine cycle during $40 \%$ and $30 \%$ of the total time respectively will be enough to achieve the same revenue as the simple cycle.

Moreover, as the running time increases beyond this point, the recuperative cycle project will be profitable with a higher return wealth comparing with the simple cycle. For example and in the case of a recuperator capital cost of $40 \%$ lower than that of the linear value, the difference between the NPV of recuperative cycle and simple cycle has increased from approximately $\$ 25.953 \mathrm{M}$ to $\$ 46.753 \mathrm{M}$ by raising the utilization factor from $70 \%$ to $100 \%$.

\subsection{Recuperator Effectiveness Impact}

The influences of effectiveness on the thermal efficiency and recuperator size have been covered in previous two chapters. In this section, the impacts of effectiveness on the net present value (NPV) will be investigated at constant pressure drop as the design point.

As a result of the increase in recuperator size with the effectiveness rise, the capital cost of recuperator increases hence the required time to breakeven point goes up as shown in figures 11 and 12. Based on figure 11 and at full load condition and fully utilization factor, the W6BRC recuperator with $70 \%$ effectiveness is expected to achieve the highest NPV at the end of the project life and in all the cases of capital and maintenance costs. So, the recommended recuperator effectiveness which is expected to achieve a higher return wealth is $70 \%$.

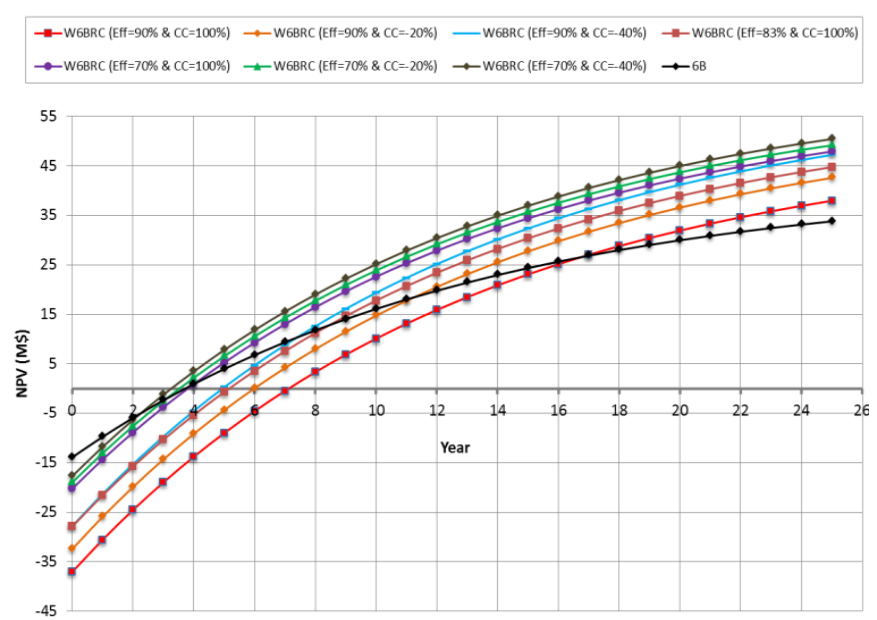

Figure 11: Effect of Effectiveness on NPV of W6BRC at $\mathrm{FL}$ and $+30 \% \mathrm{MC}$

Another point which has to be considered is the payback period. It is clearly shown that the payback period in the case of $70 \%$ effectiveness is relatively close to that of the simple cycle which will help to recover the initial investment in a shorter period comparing with the original design effectiveness $(83 \%)$.

Considering W7FARC recuperator, and in the case of linear capital cost, designing the recuperator with $70 \%$ effectiveness is expected also to achieve the highest NPV among the three cases of effectiveness with an increase of $1.1 \%$ over the actual design point. 


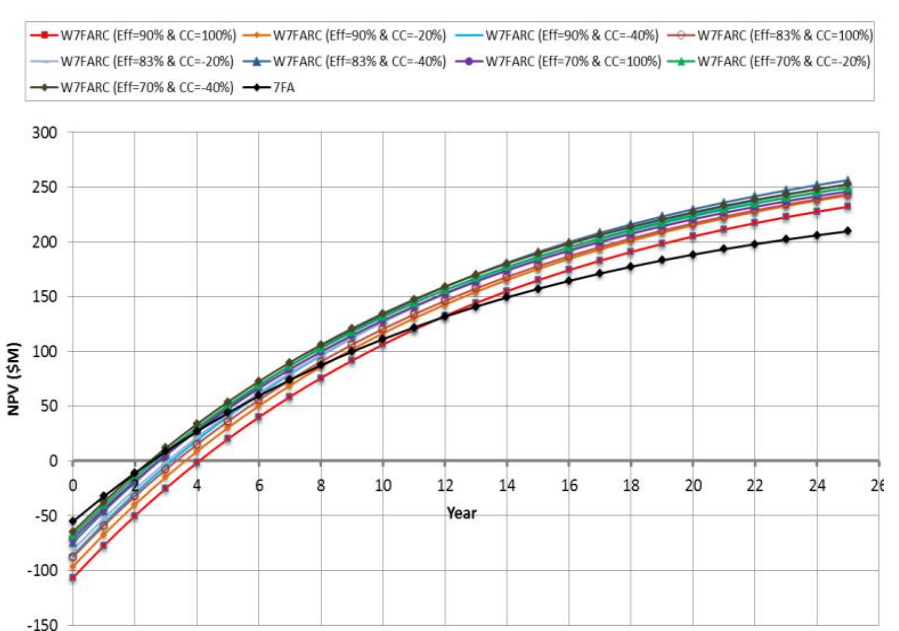

Figure 12: Effect of Effectiveness on NPV of W7FARC at FL and $+30 \% \mathrm{MC}$

An interesting observation is that at a recuperator capital cost of $80 \%$ and $60 \%$ of the total linear value, the recommended effectiveness in order to achieve the highest possible profit is $83 \%$ which is the same as the design point.

\subsection{Influences Of Recuperate Flow Velocity}

As was explained in the previous chapter, the flow velocity reduction has adverse effect on the recuperator size since it relates to the recuperator effectiveness and pressure drops. At flow velocity of $30 \mathrm{~m} / \mathrm{s}$, the capital cost of recuperative cycle is lower than that of $5 \mathrm{~m} / \mathrm{s}$ and $15 \mathrm{~m} / \mathrm{s}$ since the required recuperator size at $30 \mathrm{~m} / \mathrm{s}$ is smaller as shown in figures 13 and 14. Moreover, the required time to achieve the breakeven NPV is increasing as the flow velocity decreases.

Considering figure 13 and although that the initial capital cost at $30 \mathrm{~m} / \mathrm{s}$ flow velocity is relatively lower, designing the W6BRC recuperator with this velocity is not recommended economically since the recuperation will not be able to achieve a higher return wealth comparing with that of simple cycle at the end of project life. This is generally due to a higher pressure drops at this velocity which cause a greater reduction in the power output and thermal efficiency.

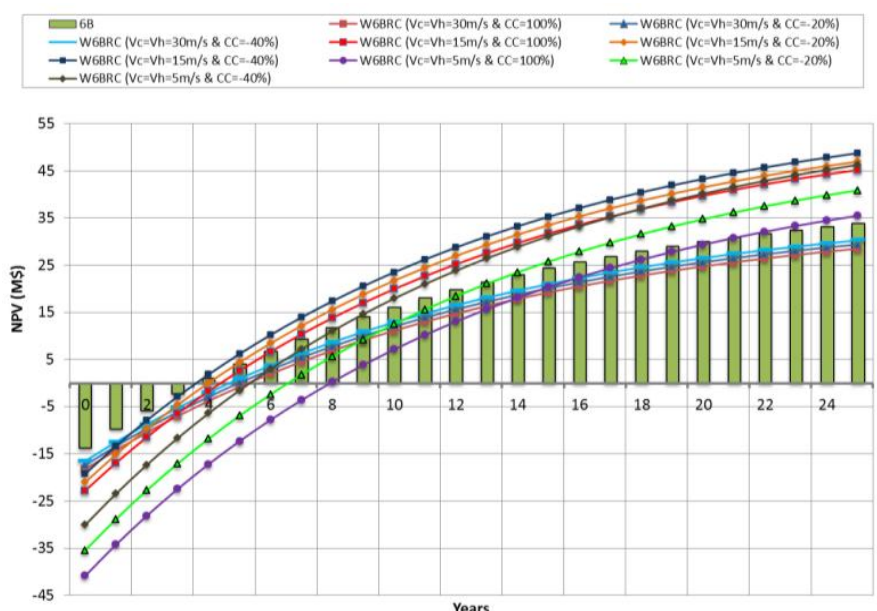

Figure 13: Effect of Flow Velocity on NPV of W6BRC at $\mathrm{FL}$ and $+30 \% \mathrm{MC}$
Moreover, the highest net present value in all the capital cost cases can be achieved by designing the W6BRC recuperator with a flow velocity of $15 \mathrm{~m} / \mathrm{s}$. So, selecting a recuperator with $15 \mathrm{~m} / \mathrm{s}$ flow velocity is expected to achieve a higher return wealth comparing with the proposed design by the manufacture $\left(\mathrm{V}_{\mathrm{c}}=3.62 \mathrm{~m} / \mathrm{s} \& \mathrm{~V}_{\mathrm{h}}=20.75 \mathrm{~m} / \mathrm{s}\right)$ by an increase ranging between $\$ 0.406 \mathrm{M}$ to $\$ 3.994 \mathrm{M}$. However, the effect of maintenance cost is can be considered as ainsignificant comparing with the power revenue and fuel cost.

One issue which should be addressed also is the machine availability effect. Introducing the heat exchanger in the gas turbine cycle can lead to reduce the operation availability due to the components increase. Figure 14 demonstrates the influence of machine availability on the overall NPV of recuperative cycle at $30 \mathrm{~m} / \mathrm{s}$ flow velocity.

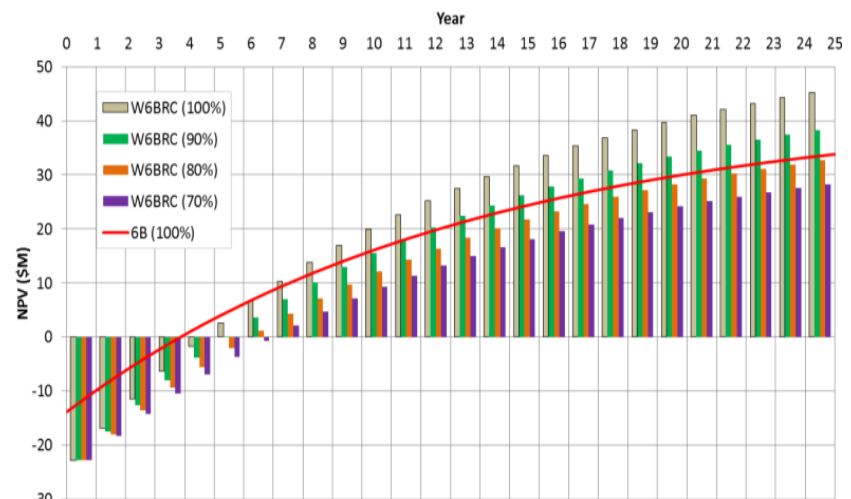

Figure 14: Effect of Machine Availability on NPV of W6BRC at Selected Heat Exchanger Design

As the availability of the cycle decreases the NPV value of the recuperative cycle is getting closer to the simple cycle value leading to lower economic viability. However, when the overall availability decreases by around $18 \%$ from that of simple cycle, the predicted cumulative discounted cash flow of the recuperative cycle matches the value of simple cycle. Hence, the heat exchanger retrofit process is not recommended at lower than this percentage.

Similarly and in the case of W7FARC, the recuperator with a flow velocity of $30 \mathrm{~m} / \mathrm{s}$ is not recommended economically at all the cases of capital and maintenance costs as shown in figure 15 .

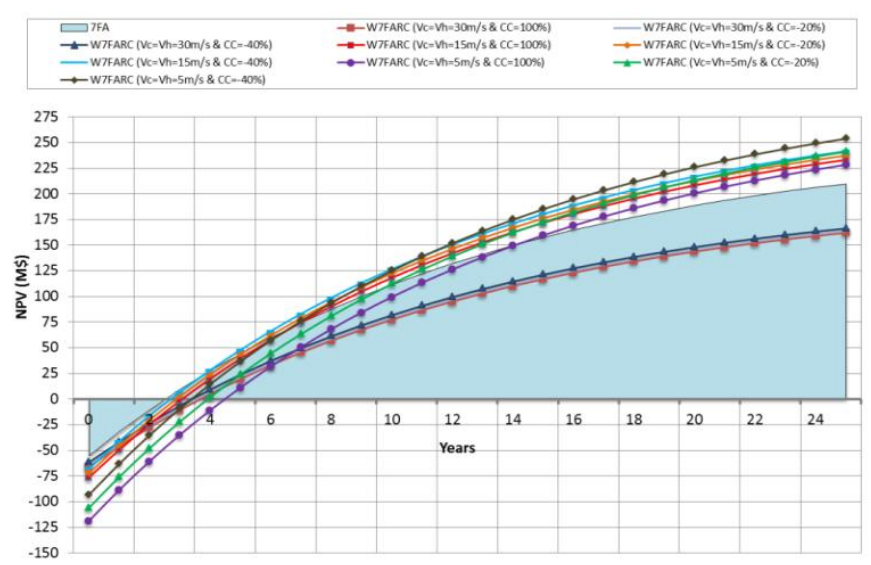

Figure 15: Effect of Flow Velocity on NPV of W7FARC at FL and $+30 \% \mathrm{MC}$ 
Additionally, designing the W7FARC recuperator with a flow velocity of $15 \mathrm{~m} / \mathrm{s}$ is expected to achieve the highest possible return wealth comparing with other velocities especially at a linear recuperator capital cost.

In the case of a non-linear recuperator capital cost, investing on a recuperator with larger size and with a flow velocity of $5 \mathrm{~m} / \mathrm{s}$ has the greatest economic benefit at the end of project life even that its initial capital cost is the highest. However, by comparing the achieved NPV at all three cases of flow velocities with the original design velocity $\left(\mathrm{V}_{\mathrm{c}}=3.83 \mathrm{~m} / \mathrm{s}\right.$ $\left.\& V_{h}=6.51 \mathrm{~m} / \mathrm{s}\right)$, the selected recuperator at design point is expected to achieve the highest return wealth at all cases of capital and maintenance costs.

\section{CONCLUSION}

This study introduced a new integrated approach to evaluate the heat exchanger retrofit on existing industrial gas turbine based on technical and economic prospective. The economic viability of recuperation has been assessed using Net Present Value (NPV) method and with consideration of the derived heat exchanger design alternatives. A higher cumulative discounted cash flow was observed with recuperative cycle with different breakeven time. It was found that at full load and $100 \%$ utilization factor conditions, the NPV of the simple cycle of the engine $\mathrm{W} 6 \mathrm{~B}$ reached to $\$ 33.8 \mathrm{M}$ at the end of the project life comparing with approximately $\$ 44.8 \mathrm{M}$ of the recuperative cycle. However, the difference between the NPV of recuperative and simple cycles was greater in the case of W7FA engine which was ranging between $\$ 33.9 \mathrm{M}$ and $\$ 46.8 \mathrm{M}$. Furthermore, the payback period of the recuperative cycle in the case of W6BRC has increased by approximately one year over that of simple cycle. Regarding the engine W7FARC, there was no significant rise in the payback period over the original simple cycle.

The conducted economic analysis revealed that the return wealth of W6BRC can be increased by investing on the recuperator with a cold and hot flow velocity of $15 \mathrm{~m} / \mathrm{s}$ instead of using the proposed design by the manufacture. This is recommended to raise the net present value of the original recuperative cycle by about $1 \%$ to $9 \%$. However, the reduction in the operation availability of the recuperative gas turbine cycle by about $18 \%$ over the simple cycle gas turbine caused the NPV of both cycles to be equal On the other hand, the proposed recuperator design for the engine W7FARC $\left(\mathrm{V}_{\mathrm{c}}=3.83 \mathrm{~m} / \mathrm{s} \quad \& \mathrm{~V}_{\mathrm{h}}=6.51 \mathrm{~m} / \mathrm{s}\right)$ achieved the greatestNPV at all cases of capital and maintenance costs.

\section{ACKNOWLEDGMENTS}

The first author would like to thank Petroleum Development Oman and Canfield University for supporting this study.

\section{NOMENCLATURE}

\begin{tabular}{ll}
\multicolumn{1}{c}{$V$} & Flow Velocity \\
$w$ & Recuperator Weight \\
$D F$ & Discounted Factor \\
$r_{i}$ & Interest Rate \\
$\varepsilon$ & Effectiveness \\
$n$ & Project Life in Years.
\end{tabular}

$\begin{array}{ll}\text { ABBREVIATIONS } \\ \text { CC } & \text { Capital Cost } \\ \text { DCF } & \text { Discounted Cash Flow } \\ \text { FL } & \text { Full Load } \\ \text { GT } & \text { Gas Turbine } \\ \text { HX } & \text { Heat Exchanger } \\ \text { MC } & \text { Maintenance Cost } \\ \text { UF } & \text { Utilization Factor } \\ \text { NPV } & \text { Net Present Value } \\ \text { OEM } & \text { Original Equipment Manufacture } \\ \text { PS } & \text { Physical Size } \\ \text { P } & \text { Power Output } \\ \text { PR } & \text { Pressure Ratio } \\ \text { RC } & \text { Recuperative Cycle } \\ \text { SC } & \text { Simple Cycle } \\ \text { M } & \text { Million }\end{array}$

\section{SUBSCRIPTS}

$\begin{array}{ll}\mathrm{c} & \text { Cold Stream } \\ \mathrm{h} & \text { Hot Stream } \\ 1 & \text { Inlet of Recuperator Stream } \\ 2 & \text { Outlet of Recuperator Stream } \\ \mathrm{s} & \text { Shell Side } \\ \mathrm{t} & \text { Tube Side } \\ A C & \text { Compressor } \\ G T & \text { Turbine } \\ C C & \text { Combustion Chamber } \\ a c t & \text { Actual }\end{array}$

\section{REFERENCES}

[1]. Ruixian, C. (1989). New Analysis of Recuperation Gas Turbine Cycles, Journal of Engineering Thermophysics.

[2]. Cai, R. (1998). A new analysis of recuperative gas turbine cycles. Proceedings of the Institution of Mechanical Engineers, Part A: Journal of Power and Energy, 212(4), 289-296.

[3]. A.Bejan,G.Tsatsaronis andM. J. Moran (1996). Thermal design and optimization. John Wiley \& Sons.

[4]. Khatib, Hisham (2003),Economic Evaluation of Projects in the Electricity Supply Industry, IEE Power \& Energy Series 44.

[5]. Zhou Guo-Yan, Wu En and Tu Shan-Tung (2008), Techno-economic study on compact heat exchangers, International Journal of Energy Research, Int. J. Energy Res.2008; 32:1119-1127

[6]. Pedro Belli, Jock Anderson, Howard Barnum, John Dixon and Jee-Peng Tan (1997), Handbook on Economic Analysis of Investment Operations, 
Learning and Leadership Center.

[7]. M.Ameri and N.Enadi, (2012), Thermodynamic modeling and second law based performance analysis of a gas turbine power plant (exergy and exergoeconomic analysis), Journal of Power Technologies, 92(3), 183-191.

[8]. Energy Sector Management Assistance Program (2009), Study of EquipmentPrices in thePower Sector, ESMAP Technical Paper 122/09, Washington, U.S.A

\section{BIOGRAPHIES}

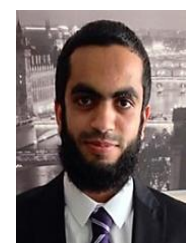

Researcher in Cranfield University

Bedford, UK

Rotating Equipment Engineer in Petroleum

Develpemt Oman

E.w.albusaidi@cranfield.ac.uk

$\mathrm{T}:+44$ (0) 1234752171

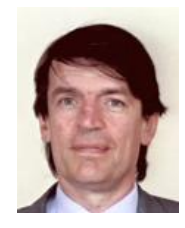

Head of Propulsion Engineering Centre

School of Aerospace, Transport and Manufacturing

Cranfield University, Bedford, UK

E: p.pilidis@cranfield.ac.uk

T: +44 (0) 1234754646 